\title{
BCAVe Regimen
}

National Cancer Institute

\section{Source}

National Cancer Institute. BCAVe Regimen. NCI Thesaurus. Code C161930.

A chemotherapy regimen consisting of bleomycin, lomustine, doxorubicin, and vinblastine that may be used in the treatment of Hodgkin lymphoma (HL). 